\title{
Evaluation of genetic variability in in vitro sodium azide-induced Dendrobium 'Earsakul' mutants
}

\author{
A. Wannajindaporn, O. Poolsawat, W. Chaowiset and P.A. Tantasawat \\ School of Crop Production Technology, Suranaree University of Technology, \\ Muang District, Nakhon Ratchasima, Thailand \\ Corresponding author: P.A. Tantasawat \\ E-mail: piyada@sut.ac.th
}

Genet. Mol. Res. 13 (3): 5333-5342 (2014)

Received May 27, 2013

Accepted November 1, 2013

Published July 24, 2014

DOI http://dx.doi.org/10.4238/2014.July.24.12

\begin{abstract}
In vitro mutagenesis of Dendrobium 'Earsakul' was carried out by incubating the protocorm-like bodies in $0-5 \mathrm{mM}$ sodium azide for $1 \mathrm{~h}$. Twenty-eight putative mutants were evaluated for genetic variability compared to untreated control plants using inter-simple sequence repeat (ISSR) analysis. Polymorphic fragments were produced by 9 of 12 ISSR primers. A total of 173 amplified ISSR fragments varying in size from 140 to $5000 \mathrm{bp}$ were obtained, 39 of which were polymorphic $(22.5 \%)$. Of the 28 putative mutants, 15 $(53.6 \%)$ showed altered genetic profiles compared to control and were identified as mutants. These results suggest that sodium azide can be effectively utilized to generate mutants in Dendrobium 'Earsakul', and ISSR provides a powerful tool that allows efficient early detection of these mutants. The identified mutants are currently being multiplied for further evaluation of their horticultural characteristics.
\end{abstract}

Key words: Inter-simple sequence repeat; Molecular marker; Mutagenesis; Orchid; Tissue culture 


\section{INTRODUCTION}

Dendrobium is the most popular commercial orchid in Thailand. New varieties with improved flower quality and yield as well as unique floral characteristics (size, form, and color), which have been produced through hybridization or mutation, are in constant demand. Mutations could generate phenotypic variations in both vegetative and reproductive characteristics (shape, color, and size of leaves and flowers), yield, hardiness, and resistance to diseases and insect pests. This approach is particularly useful for Dendrobium improvement because it is highly heterozygous and is genetically diverse. Mutations can add desirable trait(s) into an otherwise excellent cultivar without altering its entire genetic makeup as well as enhance genetic variability. Induced mutations have proven successful in several plants such as banana, sunflower, Brassica rapa subspecies yellow sarson, and Dendrobium (Khosravi et al., 2009; Khatri et al., 2011; Kumar et al., 2011; Mostafa and Alfrmawy, 2011). Chemical mutagens including ethyl methanesulfonate and sodium azide $\left(\mathrm{NaN}_{3}\right)$ are efficient at inducing mutations in several plants without requiring expensive equipment. $\mathrm{NaN}_{3}$ is one of the most powerful mutagens that causes point mutations (transitions and transversions), especially AT to GC, resulting in amino acid changes that may modify the function of proteins and alter phenotypes. The mutagenicity is mediated through the production of an organic metabolite of azide compound, which interacts with DNA, creating point mutations in the genome. In addition, it also induces chromosome aberrations, predominantly translocations, lagging chromosome, bridges, and sticky chromosomes, and polyploidization. $\mathrm{NaN}_{3}$ has been applied to improve agronomic/horticultural characteristics, yield, contents of fatty acid or anthocyanin, and resistance/tolerance to various abiotic/biotic stresses in several plants (Al-Qurainy and Khan, 2009). In the terrestrial orchid (Spathoglottis plicata), treating seeds with $\mathrm{NaN}_{3}$ induced strikingly attractive flower color modifications (Roy and Biswas, 2005). In vitro mutagenesis, combining mutations with in vitro culture, enables the generation of sufficient variation in large populations of mutants to ensure the discovery of mutants with desirable trait(s), as well as rapid clonal multiplication (Khawale and Singh, 2006; Barakat and El-Sammak, 2011; Bidabadi et al., 2012).

The selection of mutants is traditionally accomplished using morphological characteristics; however, this method of selection is time-consuming and unreliable because of environmental effects. In addition, mutations of many plant genes may not lead to easily identifiable phenotypes, may be highly pleiotropic, or may be developmentally dependent. Therefore, early selection of the mutants based on morphological characteristics from large putative mutant populations is often complicated. In contrast, direct selection based on DNA markers circumvents these limitations, thereby increasing the efficiency as well as reducing the cost of selection. Several DNA markers have been used to identify mutants and somaclonal variants including amplified fragment length polymorphism, random amplified polymorphic DNA, and inter-simple sequence repeat (ISSR) (Khawale and Singh, 2006; Khosravi et al., 2009; Kuchma et al., 2011; Kumar et al., 2011; Mostafa and Alfrmawy, 2011; Bidabadi et al., 2012). ISSR exploits primers that are complementary to the simple sequence repeats that anneal to and amplify DNA sequences between the adjacent inversely oriented repeats. ISSRs are randomly distributed throughout the genome, allowing the detection of multiple loci simultaneously, and requiring no prior sequence information (Reddy et al., 2002). The highly polymorphic nature, simplicity, rapidity, and cost-effectiveness also make ISSRs particularly suitable for the identification of randomly occurring mutations. In ISSR analysis, the patterns 
of amplified DNA fragments are dependent on the primer sequence as well as the genomic DNA sequence being analyzed. Mutations resulting from deletions/duplications or single nucleotide changes at the primer binding sites can be identified. In orchids, ISSRs have been utilized to assess the level of genetic diversity in cultivated spring orchid (Cymbidium goeringii), to estimate genetic stability of micropropagated jewel orchid (Anoectochilus formosanus), and to determine the phylogenetic relationship of Dendrobium species (Wang et al., 2009; Zhang et al., 2010). In this study, we evaluated the effectiveness of ISSRs in detecting and fingerprinting Dendrobium 'Earsakul' mutants induced by in vitro mutagenesis of protocorm-like bodies (PLBs) using different concentrations of $\mathrm{NaN}_{3}$, and we assessed the genetic variability of these mutants.

\section{MATERIAL AND METHODS}

\section{Plant materials}

PLBs from clonal propagation of Dendrobium 'Earsakul' were treated with 0 (control),

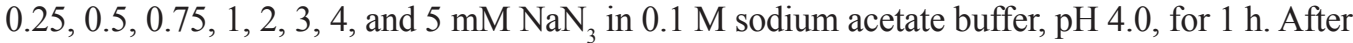
the mutagen treatment, they were transferred to modified VW (Vacin and Went, 1949) medium (Tantasawat et al., 2010) and maintained at $27^{\circ} \pm 2^{\circ} \mathrm{C}$ with a 16 -h photoperiod provided by cool-white fluorescent tubes at a photosynthetic photon flux density of $100 \mu \mathrm{mol} \cdot \mathrm{m}^{-2} \cdot \mathrm{s}^{-1}$ until reaching the 4- to 6-leaf stage. Twenty-eight putative mutants were randomly selected from all $\mathrm{NaN}_{3}$ concentrations (M1 and M2 from $0.25 \mathrm{mM}, \mathrm{M} 3$ and M4 from $0.5 \mathrm{mM}$, M5 and M6 from $0.75 \mathrm{mM}, \mathrm{M} 7-\mathrm{M} 11$ from $1 \mathrm{mM}, \mathrm{M} 12$ and M13 from $2 \mathrm{mM}$, M14-M19 from $3 \mathrm{mM}$, M20-M22 from $4 \mathrm{mM}$, and $\mathrm{M} 23-\mathrm{M} 28$ from $5 \mathrm{mM} \mathrm{NaN}_{3}$ ). In addition, 10 untreated controls (C1-C10) were randomly selected from $0 \mathrm{mM} \mathrm{NaN}_{3}$.

\section{DNA isolation}

Young leaves were freshly harvested from 28 putative mutants and 10 controls and rapidly frozen in liquid $\mathrm{N}_{2}$. DNA extraction was performed by the cetyltrimethylammonium bromide (CTAB) method modified from Miaobin et al. (2009). DNA was quantified by spectrophotometry using an ND-1000 spectrophotometer (NanoDrop Technologies, Inc., Wilmington, DE, USA) to adjust the final concentration to $25 \mathrm{ng} / \mu \mathrm{L}$ for use in polymerase chain reaction $(\mathrm{PCR})$ analysis.

\section{ISSR analysis}

Twelve ISSR primers homologous to microsatellite repeats and containing additional selective anchor nucleotides that were developed from the University of British Columbia were chosen for the analysis (Table 1). These primers are homologous to microsatellite repeats (AC, AG, AT, CA, GA, or TG) anchored at the 3'-end by 1-2 nucleotides, most of which have been used successfully to determine the genetic diversity in wild C. goeringii (Orchidaceae) populations (Xiaohong et al., 2007). Three of these contained an AG repeat motif, three contained a GA repeat motif, two contained an AC repeat motif, two contained a CA repeat motif, and one each contained an AT or TG repeat motif. Each $20-\mu \mathrm{L}$ PCR mix contained $25 \mathrm{ng}$ ge- 
nomic DNA template, $1 \mathrm{X}$ buffer $\left(75 \mathrm{mM}\right.$ Tris- $\mathrm{HCl}$, pH 9.0, $\left.50 \mathrm{mM} \mathrm{KCl}, 20 \mathrm{mM}\left(\mathrm{NH}_{4}\right)_{2} \mathrm{SO}_{4}\right)$, $2.5 \mathrm{mM} \mathrm{MgCl}, 200 \mu \mathrm{M}$ of each dNTP, $1 \mathrm{U}$ Geneaid DNA polymerase (Geneaid Biotech Ltd., Taipei, Taiwan), and $4 \mu \mathrm{M}$ of each ISSR primer. The PCR mixes were subjected to amplification with initial denaturation at $94^{\circ} \mathrm{C}$ for $5 \mathrm{~min} ; 45$ cycles of denaturing at $94^{\circ} \mathrm{C}$ for $45 \mathrm{~s}$, annealing at $48^{\circ}-58^{\circ} \mathrm{C}$ (Table 1) for $45 \mathrm{~s}$, extension at $72^{\circ} \mathrm{C}$ for $90 \mathrm{~s}$; and a final extension at $72^{\circ} \mathrm{C}$ for 7 min in a ThermoHybaid Px2 thermocycler (Thermo Fisher Scientific, Inc., Waltham, MA, USA). The amplified products were revealed on $6 \%$ denaturing polyacrylamide gel and detected by silver nitrate according to Sambrook and Russell (2001). Molecular weights of the DNA bands were estimated using $1 \mathrm{~kb}$ plus DNA ladder (Gibco-BRL, Gaithersburg, MD, USA) as standards.

\begin{tabular}{|c|c|c|c|c|c|c|}
\hline Primer & Primer sequence & $\begin{array}{c}\text { Annealing } \\
\text { temperature }\left({ }^{\circ} \mathrm{C}\right)\end{array}$ & $\begin{array}{l}\text { No. of } \\
\text { total bands }\end{array}$ & $\begin{array}{c}\text { No. of } \\
\text { polymorphic bands }\end{array}$ & $\begin{array}{c}\text { Polymorphism } \\
(\%)\end{array}$ & $\begin{array}{l}\text { Amplified band size } \\
\text { (bp) }\end{array}$ \\
\hline ISSR 801 & $(\mathrm{AT})_{8} \mathrm{~T}$ & 53 & 11 & 0 & 0.0 & $240-3800$ \\
\hline ISSR 807 & $(\mathrm{AG})_{8} \mathrm{~T}$ & 53 & 13 & 2 & 15.4 & $210-3400$ \\
\hline ISSR 811 & $(\mathrm{GA}){ }_{8} \mathrm{C}$ & 53 & 23 & 9 & 39.1 & $540-4100$ \\
\hline ISSR 812 & $(\mathrm{GA})_{8}^{\circ} \mathrm{A}$ & 53 & 16 & 2 & 12.5 & $160-3800$ \\
\hline ISSR 817 & $(\mathrm{CA})_{8} \mathrm{~A}$ & 53 & 13 & 1 & 7.7 & $190-4100$ \\
\hline ISSR 818 & $(\mathrm{CA})_{8} \mathrm{G}$ & 53 & 14 & 6 & 42.9 & $200-4400$ \\
\hline ISSR 825 & $(\mathrm{AC})_{8} \mathrm{~T}$ & 53 & 16 & 5 & 31.3 & $200-4800$ \\
\hline ISSR 827 & $(\mathrm{AC})_{8} \mathrm{G}$ & 53 & 23 & 11 & 47.8 & $240-4100$ \\
\hline ISSR 829 & $(\mathrm{TG})_{8} \mathrm{C}$ & 58 & 11 & 1 & 9.1 & $220-4000$ \\
\hline ISSR 834 & $(\mathrm{AG})_{8}^{8} \mathrm{YT}$ & 58 & NR & NR & NA & NA \\
\hline ISSR 835 & $(\mathrm{AG})_{8}^{8} \mathrm{YC}$ & 48 & 18 & 2 & 11.1 & $140-5000$ \\
\hline ISSR 840 & $(\mathrm{GA})_{8}^{8 T}$ & 48 & 15 & 0 & 0.0 & $200-3800$ \\
\hline Total & & & 173 & 39 & & \\
\hline Average & & & 15.7 & 3.6 & 19.7 & \\
\hline
\end{tabular}

$\mathrm{NA}=$ not available; $\mathrm{NR}=$ non-reproducible $\mathrm{Y}=$ pyrimidines $(\mathrm{C}, \mathrm{T})$.

\section{Data scoring, cluster, and principal coordinate analysis}

DNA bands with the same mobility were treated as identical fragments. Because all 10 controls gave similar DNA profiles with all primers, only a representative C1 was used for the cluster and coordinate analysis. A clearly amplified band was coded as 0 or 1 for its absence or presence, respectively. Similarity coefficients between various putative mutants and a control, in a pairwise comparison, were computed using Jaccard's coefficient, and the resulting similarity matrix was further analyzed using the unweighted pair group method with arithmetic average (UPGMA) clustering algorithm; the computations were carried out using NTSYSpc version 2.2 (Rohlf, 2000). The goodness of fit of the putative mutants and control to a specific cluster in the UPGMA cluster analysis was determined by the Mantel correlation test (Mantel, 1967). A correlation value ( $r$ ) greater than 0.5 is considered to be statistically significant at the 0.01 probability level if the number of observed taxonomic units exceeds 15 (Lapointe and Legendre, 1992).

NTSYSpc version 2.2 (Rohlf, 2000) was also used to perform principal coordinate analysis (PCoA) to show multiple dimensions of the distribution of the genotypes in a scatterplot (Keim et al., 1992). This multivariate approach was used to complement the information 
obtained from cluster analysis because it is more informative regarding distances among major groups (Tar'an et al., 2005).

\section{RESULTS AND DISCUSSION}

The genetic variability of 28 putative 'Earsakul' mutants, which were obtained from $\mathrm{NaN}_{3}$ treatment, and 10 controls $(0 \mathrm{mM})$ were analyzed using 12 ISSR primers. One of the primers, ISSR 834, amplified complex non-reproducible DNA patterns and was withdrawn from further analysis. Of the 11 ISSR primers that produced clear and reproducible amplicon profiles, 9 were polymorphic and 2 were monomorphic (Table 1). All 10 controls gave similar DNA profiles with all 11 primers, suggesting no evidence of somaclonal variation in the absence of $\mathrm{NaN}_{3}$ treatment. The 11 primers amplified a total of 173 fragments across all genotypes, of which 39 fragments were polymorphic, giving a polymorphism percentage of $22.5 \%$. On average, 15.7 total fragments, varying from 11 to 23 , and 3.6 polymorphic fragments, ranging from 0 to 11, were amplified per primer. The length of amplified ISSR fragments ranged from $140 \mathrm{bp}$ (ISSR 835) to $5000 \mathrm{bp}$ (ISSR 835). ISSR 827 gave the highest percentage of polymorphism (47.8\%), followed by ISSR 818 (42.9\%) and ISSR 811 (39.1\%) (Table 1). Using the 9 polymorphic ISSR primers, $15(53.6 \%)$ of 28 putative mutants induced by $0.25-5 \mathrm{mM} \mathrm{NaN}_{3}$ showed altered amplified DNA profiles compared to the $0 \mathrm{mM}$ control and were identified as mutants. Unique bands were found in 6 mutants: one band in M2 and M7, three bands in M21, five bands in M18, six bands in M10, and eight bands in M27. These genotype-specific bands were amplified from six primers (ISSR $807,811,818,825,827$, and 835) and are very valuable for DNA fingerprinting and identifying these mutants (Table 2).

The polymorphic bands were used to construct a dendrogram based on cluster analysis using UPGMA. The grouping of mutants and the control in the dendrogram indicates the genetic distinctness of the genotypes studied as they were placed in different clusters/groups. The Mantel test with a cophenetic correlation coefficient value of $0.97(\mathrm{P}<0.01)$ indicated that data in the similarity matrix were well represented by the dendrogram. The dendrogram grouped the 28 putative mutants and a control into three clusters and five separate individuals at the genetic similarity level of 0.97 (Figure 1). The majority of putative mutants (16) were grouped into cluster I along with the control. This cluster was divided into two subclusters (IA and IB). Subcluster IA consisted of 13 putative mutants, M1, M3, M4, M5, M6, M8, M11, M12, M13, M15, M19, M24, and M26, which were genetically identical to the control, and M22 while M16 and M28 constituted cluster IB. Cluster II grouped M2 and two genetically similar mutants (M9 and M23) together with M25. Cluster III consisted of the two genetically identical mutants, M14 and M20, and M17. The remaining mutants, M7, M10, M18, M21, and M27 could not be grouped into any clusters.

Jaccard's genetic similarity coefficients among the pairwise combinations of genotypes ranged from 0.655 (M18 and M27) to 1.0 (3 groups of 18 genotypes), with a mean of 0.933 . The mutant M27 was found to be the most dissimilar from the control (genetic similarity coefficient $=0.755)$, followed by M10 (0.830), M18 (0.852), and M21 (0.912). Thirteen putative mutants displayed identical genetic profiles with the control at all 173 loci evaluated and may represent genetically unaltered plants. Two pairs of mutants (M9 and M23, and M14 and M20) had similar coefficients (1) with each other within a pair, but they were distinct from the control (Table 3). 


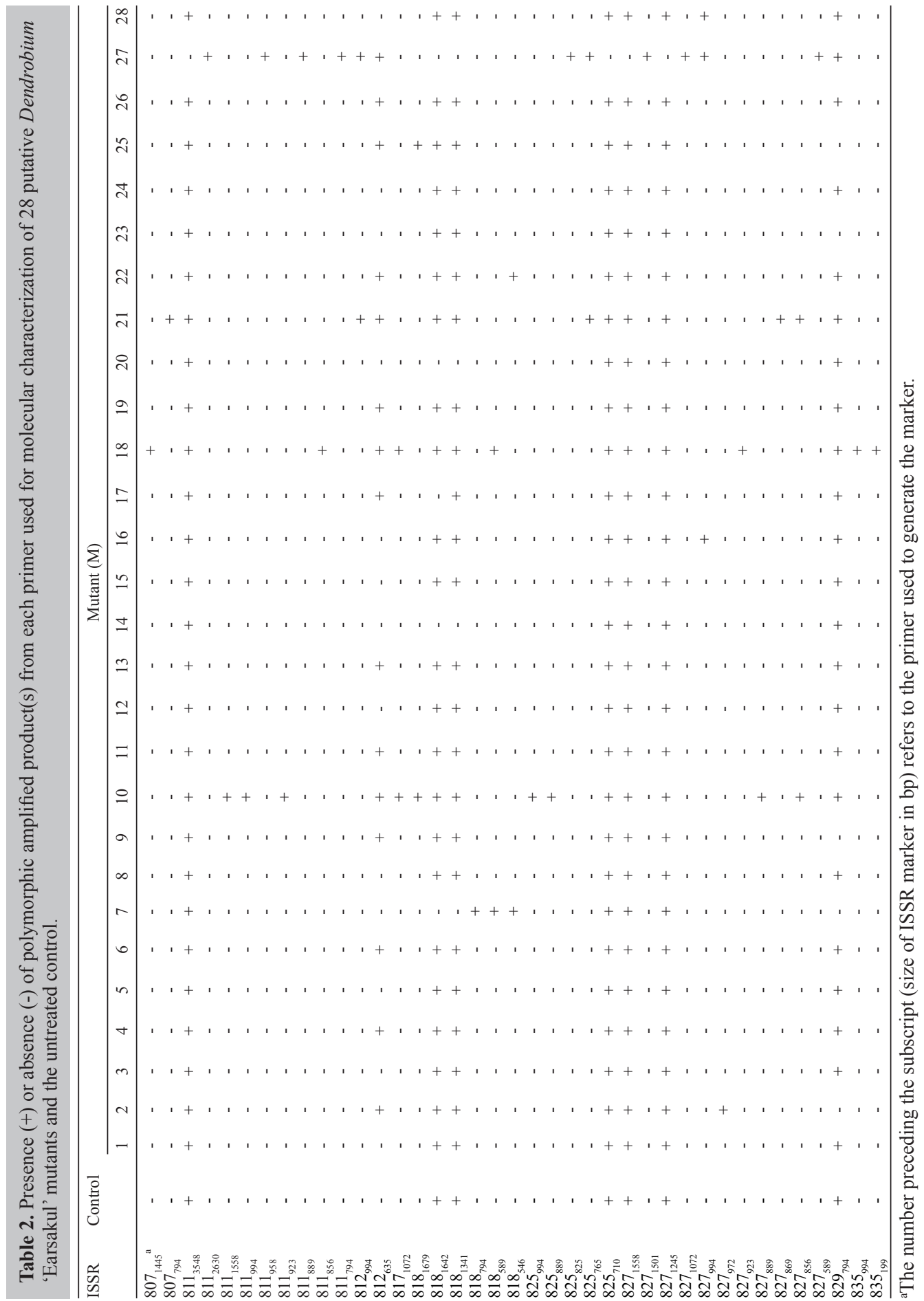


It is interesting to note that no relationship was found between the genetic similarity/ distance and the concentrations of $\mathrm{NaN}_{3}$ used, although $\mathrm{NaN}_{3}$ was known to induce chromosome aberrations, which increased with increasing $\mathrm{NaN}_{3}$ concentrations (Al-Qurainy and Khan, 2009). However, to determine the relationship more accurately, a larger population of mutants is needed; this is currently under investigation.

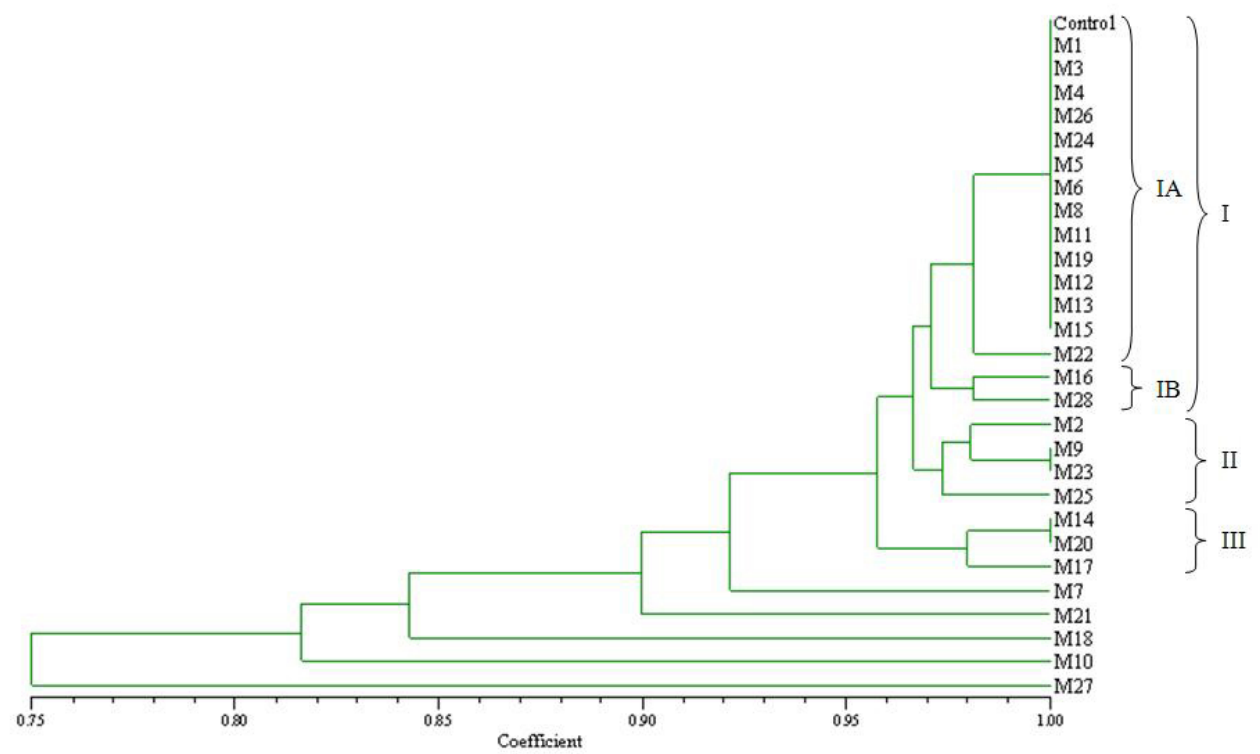

Figure 1. ISSR-derived dendrogram of 28 putative Dendrobium 'Earsakul' mutants (M1-M28) and the untreated control.

PCoA was used to identify multidimensional relationships that describe portions of the genetic variance in a data set. Three-dimensional plots of PCoA based on ISSR markers were generally consistent with the UPGMA cluster analysis; however, the separation of M27 from the rest was more clearly observed (Figure 2). In addition, the genotypes in cluster I were intermixed into the same group rather than separated into 2 subclusters. The three coordinates explained $30.3,16.5$, and $14.0 \%$ with a total of $60.8 \%$ of the total variance.

Although low levels of genetic variation were found among putative mutants ( 23 of them had more than $95 \%$ genetic similarity), ISSR was sensitive enough to discriminate 11 of them. Similarly, mutants or somaclonal variants have been successfully identified using ISSR analysis in several plants including B. rapa subspecies yellow sarson and A. formosanus (Zhang et al., 2010; Kumar et al., 2011).

The absence of ISSR fragments or the presence of additional ISSR fragments in 15 mutants may result either from the loss/gain of primer binding sites as a result of changes in the nucleotide sequences (e.g., point mutations) or changes that alter the size or prevent the successful amplification of a target DNA (e.g., deletions, duplications, inversions, or translocations). These mutants will be transferred to a greenhouse for further evaluation of desirable traits and multiplication. It should be noted that changes in ISSR profiles may not reflect changes in morphological traits. The relationship between genetic and phenotypic alterations of these mutants will also be evaluated in the future. 
A. Wannajindaporn et al.

5340



Genetics and Molecular Research 13 (3): 5333-5342 (2014)

CFUNPEC-RP www.funpecrp.com.br 


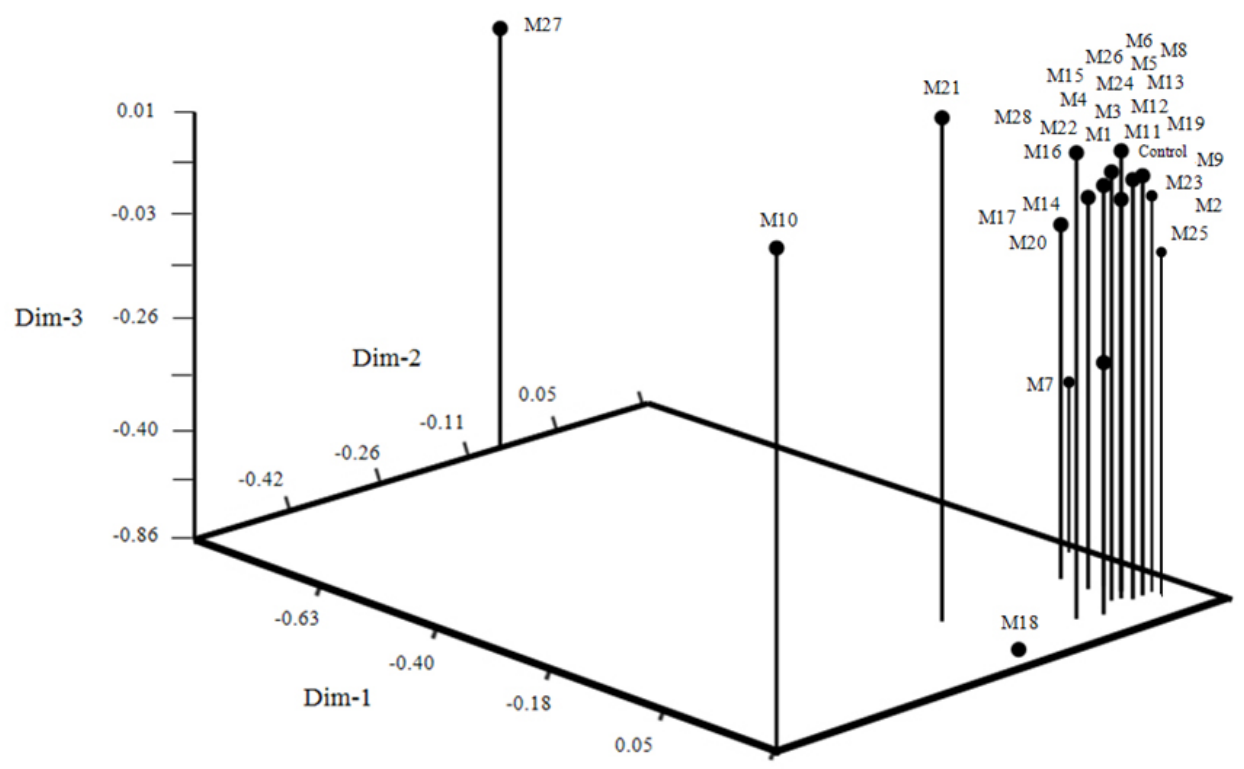

Figure 2. ISSR-derived three-dimensional plot based on the first three principal coordinates from a principal coordinate analysis of 28 putative Dendrobium 'Earsakul' mutants and the untreated control.

\section{CONCLUSION}

Our results indicate the effectiveness of ISSR markers for the identification of Dendrobium mutants obtained from $\mathrm{NaN}_{3}$-induced PLBs that could allow earlier selection and reduction of the mutant population size. As far as we know, this is the first report of mutant identification using ISSRs in Dendrobium. The combined utilization of ISSR analysis together with in vitro mutagenesis as a source for inducing genetic variation provides a useful tool for future improvement of Dendrobium.

\section{ACKNOWLEDGMENTS}

Research supported by the Higher Education Research Promotion and National Research University Project of Thailand, Office of the Higher Education Commission, Ministry of Education, and grants from the Thailand Research Fund and Suranaree University of Technology, Thailand.

\section{REFERENCES}

Al-Qurainy F and Khan S (2009). Mutagenic effect of sodium azide and its application in crop improvement. World Appl. Sci. J. 6: 1589-1601.

Barakat MN and El-Sammak H (2011). In vitro mutagenesis, plant regeneration and characterization of mutants via RAPD analysis in Baby's breath Gypsophila paniculata L. Aust. J. Crop Sci. 5: 214-222.

Bidabadi SS, Meon S, Wahab Z, Subramaniam S, et al. (2012). Induced mutations for enhancing variability of banana (Musa spp.) shoot tip cultures using ethyl methanesulphonate (EMS). Aust. J. Crop Sci. 6: 391-401. 
Keim P, Beavis W, Schupp J and Freestone R (1992). Evaluation of soybean RFLP marker diversity in adapted germ plasm. Theor. Appl. Genet 85: 205-212.

Khatri A, Bibi S, Dahot MU, Khan IA, et al. (2011). In vitro mutagenesis in banana and variant screening through ISSR. Pak. J. Bot. 43: 2427-2431.

Khawale RN and Singh SK (2006). Gamma rays induced in vitro mutagenesis and molecular marker-assisted selection of mutants in grapevine. Acta Hort. 725: 643-651.

Khosravi AR, Kadir MA, Kadzemin SB, Zaman FQ, et al. (2009). RAPD analysis of colchicine induced variation of the Dendrobium Serdang beauty. Afr. J. Biotechnol. 8: 1455-1465.

Kuchma O, Vornam B and Finkeldey R (2011). Mutation rates in scots pine (Pinus sylvestris L.) from the Chernobyl exclusion zone evaluated with amplified fragment-length polymorphisms (AFLPs) and microsatellite markers. Mutat. Res. 725: 29-35.

Kumar H, Anubha, Vishwakarma MK and Lal JP (2011). Morphological and molecular characterization of Brassica rapa ssp yellow sarson mutants. J. Oilseed Brassica 2: 1-6.

Lapointe FJ and Legendre P (1992). Statistic significance of the matrix correlation coefficient for comparing independent phylogenetic trees. Syst. Biol. 41: 378-384.

Mantel N (1967). The detection of disease clustering and a generalized regression approach. Cancer Res. 27: 209-220.

Miaobin Z, Lijing P and Ganqun F (2009). Study on DNA isolation from polysaccharides-rich transgenic Dendrobium. Mol. Plant Breed. 7: 209-214.

Mostafa GG and Alfrmawy AM (2011). RAPD analysis for detection and fingerprinting of sunflower mutants induced by sodium azide. Int. J. Plant Breed. Genet. 5: 277-285.

Reddy MP, Sarla N and Siddiq EA (2002). Inter simple sequence repeat (ISSR) polymorphism and its application in plant breeding. Euphytica 128: 9-17.

Rohlf FJ (2000). NTSYS-pc: Numerical Taxonomy and Multivariate Analysis System. Version 2.2. Exeter Software, Setauket.

Roy S and Biswas AK (2005). Isolation of a white flowered mutant through seed culture in Spathoglottis plicata Blume. Cytologia 70: 1-6.

Sambrook J and Russell DW (2001). Molecular Cloning: A Laboratory Manual. 3rd edN. Cold Spring Harbor Laboratory Press, Cold Spring Harbor, A9.5-A9.7.

Tantasawat P, Wannajindaporn A, Chantawaree C, Wangpunga C, et al. (2010). Chitosan stimulates growth of micropropagated plantlets. Acta Hort. 878: 205-212.

Tar'an B, Zhang C, Warkentin T, Tullu A, et al. (2005). Genetic diversity among varieties and wild species accessions of pea (Pisum sativum L.) based on molecular markers, and morphological and physiological characters. Genome 48: 257-272.

Vacin E and Went FW (1949). Some pH changes in nutrient solution. Bot. Gaz. 110: 605-613.

Wang HZ, Feng SG, Lu JJ, Shi NN, et al. (2009). Phylogenetic study and molecular identification of 31 Dendrobium species using inter-simple sequence repeat (ISSR) markers. Sci Hortic. 122: 440-447.

Xiaohong Y, Li G and Bo Y (2007). Genetic diversity of wild Cymbidium goeringii (Orchidaceae) populations from Hubei based on inter-simple sequence repeats analysis. Front. Biol. China 2: 419-424.

Zhang F, Lv Y, Dong H and Guo S (2010). Analysis of genetic stability through intersimple sequence repeats molecular markers in micropropagated plantlets of Anoectochilus formosanus Hayata, a medicinal plant. Biol. Pharm. Bull. 33 : 384-388. 